\title{
Research on Teaching Reform of Human Anatomy and Physiology Course
}

\author{
Lei Diao ${ }^{a}$, Huijie Chen ${ }^{b}$ \\ College of Pharmaceutical Engineering, Jilin Agriculture Science and Technology University, Jilin, 132101, \\ China \\ aemail: 56179115@qq.com, bemail: chenhuijie1983@163.com
}

Keywords: Anatomy and Physiology of Human Body, Teaching Reform, Specialty of Pharmaceutical Preparation, Transformation and Development

\begin{abstract}
The course of Human Anatomy and Physiology is a compulsory basic course for the pharmaceutical preparation profession. In order to meet the needs of the current transformation and development of our school, the curriculum reform of human anatomy and physiology is imperative. This paper reforms the teaching of human anatomy and physiology from the aspects of teaching content, teaching methods and teaching methods to cultivate high-quality applied talents.
\end{abstract}

\section{Introduction}

Human anatomy and physiology is an important course for applied undergraduate colleges. In the transition period of national higher education, its teaching should also be revived [1]. In recent years, its teaching has achieved certain results in teaching guiding ideology, teaching material construction, teaching methods, practical training, curriculum assessment, and teacher construction. It has laid a solid foundation for the reform of professional curriculum teaching in applied undergraduate colleges in the transition period. But compared with the high-quality application talents required for today's social development, the gap is still very large. Therefore, how to improve the teaching quality of the course and cultivate students' ability to "learn and apply" is a key issue that cannot be avoided in teaching reform [2].

\section{Teaching Content Reform}

Human anatomy and physiology is an important branch of biological sciences. It is an important interdisciplinary subject and closely related to physics, chemistry, cell biology and molecular biology. In the process of teaching, molecular biology, new concepts of biological science and technology, new theories and new methods of thinking are applied to human anatomy and physiology, injecting new vitality and vitality into the traditional curriculum system and content. Therefore, the introduction of cutting-edge knowledge and technology in the teaching content has played a positive role in the cultivation of students' innovative consciousness, and can closely match the production content, and even introduce real production tasks [3].

We will optimize the teaching content of human anatomy and physiology, reconstruct the knowledge structure system, add experimental teaching content, and leap to the independent experimental class, because the experimental teaching of human anatomy and physiology is extremely important throughout the teaching process, using vivid slides, Various teaching methods such as "specimen”, "model”, "flip chart” and microscopic observation can deepen students' understanding of theoretical knowledge [4].

\section{Teaching Method Reform}

\subsection{Logic, Reasoning, and Easy-To-Understand Teaching.}

The arrangement of human anatomy and physiology is very regular. Each chapter is inseparable according to the basic structure, basic concepts, physiological phenomena, influencing factors, and physiological adjustments. Although the physiological content is abstract, difficult to understand, 
and difficult to remember, logical reasoning of physiological content is strong [5]. According to this feature, lectures need to be logical and reasoning. Each lesson must have clear clues to bring students into interesting physiological world. For example, when we talk about the physiological significance of relatively stable arterial blood pressure, first talk about the effect of low arterial blood pressure on the human body, and then talk about the effect of high arterial blood pressure on the human body, just like chatting with classmates, normal physiology and pathophysiology are linked together. It not only includes logical reasoning, but also links knowledge together, and integrates the knowledge of each lesson to facilitate understanding and memory [6].

\subsection{Heuristic, Exploratory, Problem-Based Teaching.}

Teachers should achieve the expected results. First of all, we should start with the various life phenomena that students have experienced personally. We can also use some strange abnormal life phenomena that we have heard and heard, which is easy to attract students' interest [7]. If teachers grasp the curious inquiry psychology of young people and guide them to learn with inspiration, discussion and problems, the effect will be significant. For example, when we talk about the rhythm of the sinoatrial node, the innervation of the sinus node, and the sinus rhythm, inspire students to think, why is the sinus rhythm slower than the rhythm of the sinus node? Think for a moment, ask the students to answer, let the students' ideas follow the teacher's ideas, and let the students get the answers through their own thinking. Learn this way, remember to live. For example, why does a human heart work for a long time? Does it have an aging time? Is heart failure caused by excessive heart rate? After class, students find their own answers through the Internet. After the teacher finished breathing regulation, he asked questions. Why do you want to strengthen your breathing after you hold your breath? Why do you have to pause after a deep exhalation? Students consider after class. The presentation of these questions deeply attracted the students and drove them to find the answers to the questions. Therefore, the teacher integrates the abstract and difficult-to-understand mechanism into life, from shallow to deep, and deeply analyzes the life phenomenon at the same level. Finally, the class is given out for the students to discuss and the teacher summarizes. This not only improves the students' enthusiasm for learning, but also helps the students to deepen their memory. From the past, let him learn, and now I have to learn [8].

\subsection{Theoretical, Practical, Life-Oriented Teaching.}

The outstanding characteristics of human anatomy and physiology are closely related to people's daily life. Teachers grasp this feature and closely link the teaching content with pathological phenomena, production practice and daily life, and make esoteric, abstract and difficult physiology knowledge become Simple, specific, interesting, and understandable knowledge [9]. For example, when the teacher talks about the general physiology of neuromuscular, the principle and first aid of organophosphorus pesticide poisoning are introduced, so that the physiological knowledge is closely related to the production practice. For example, before the teacher introduces the factors affecting the formation of urine, a common pathological phenomenon is proposed. Why do patients with acute glomerulonephritis have less urine, no urine and edema? When the teacher introduced the regulation of the urinary system, he suggested that during severe exercise, large blood loss, excessive sweating, severe vomiting or diarrhea can lead to oliguria or anuria. Is the mechanism the same? When the teacher introduced the digestive physiology, why should he apply dilute hydrochloric acid when taking pepsin? These problems are very common and easy to be neglected. In the process of teaching, the theoretical knowledge is closely related to daily life, and the mechanism of these phenomena is explained. Not only the physiological knowledge is learned, but also the practical problems in life are solved, and the boring physiological knowledge is changed. It is vivid and realistic, which naturally stimulates students' interest in learning.

\subsection{Metaphor, Exaggeration, Image Teaching.}

The application of these means is also very effective. For example, the teacher compares the blood composition to "Laba porridge". The change of blood composition is likened to the ecological balance of a forest. There can not be only one plant in a forest. If there is only one kind 
of plant, the ecology will unbalance [10]. The same is true for blood. If a certain component is significantly increased, it is a pathological phenomenon such as a marked increase in white blood cells, indicating that there is an infection in the body, and an abnormal increase in abnormal white blood cells is a blood disease. The viscosity of the blood is like the thin and thick of "Laba porridge". If the "Laba porridge" is thin and easy to sprinkle, if the blood is thin, the patient with hypertension is prone to cerebral hemorrhage. If the "Laba porridge" is thick, it is easy to form a rice cooker. If the blood is thick, it is easy to form blood. It is a blood clot. The image of the relationship between the bronchi and the alveoli is like a lychee or a grape. The left heart and the right heart are referred to as the neighbors of the "one wall". The relationship between the two is exaggerated as the sound of the chicken and the dog, and the old and the dead do not interact. Otherwise, it is a congenital heart disease. This indicated that the left heart and the right heart are not connected to each other, but indirectly connects through the blood vessels.

\section{Teaching Means Reform}

\subsection{Making Electronic Preparation Lesson Plans.}

The teacher produces a complete set of standardized electronic version of the lesson plans, which can be adjusted at any time according to the needs of the teaching, and can add new knowledge points or delete lengthy content in time [11].

\subsection{Collecting Colorful Teaching Image Materials.}

Physiological research has gone from the overall level and organ level to the cellular level and molecular level. It often involves some abstract, microscopic and descriptive content [12]. It is taught in the traditional way of teaching, and students are not easy to understand and accept intuitively. Therefore, teachers should make full use of limited teaching conditions, actively collect relevant image data from various channels, and make full use of network resources to collect some development history and latest literature related to teaching.

\subsection{Using Multimedia-Assisted Classroom Instruction.}

According to the requirements of the syllabus, with reference to the teaching courseware produced by each institution, the teacher produces a set of courseware that meets the learning of our students, effectively improving the teaching quality and teaching efficiency [13].

\section{Conclusion}

I am in the transitional development period, and the training direction is oriented to closely match the market and apply high-level technical and technical talents to meet the needs of the surrounding areas and even the entire Jilin industry upgrading and social public services. Since 2016, the school has implemented a transformation model, a curriculum system around the training objectives of applied talents is set up, and the talent training program is reformed. This course is a highly applied course. It is closely related to the knowledge of pharmacy courses and requires students to have certain practical and practical ability. Therefore, it has strong application value in modern society. Human anatomy and physiology is an important course for applied undergraduate colleges. In the transition period of national higher education, its teaching should also be reinvented. This paper reforms the teaching of human anatomy and physiology from the aspects of teaching content, teaching methods and teaching methods. Furthermore, it laid a solid foundation for the reform of professional courses in applied-oriented undergraduate colleges in the transition period.

\section{References}

[1] Yan Li, Xuexia Geng. Discussion on improving the teaching quality of human anatomy and physiology [J]. Journal of Huai Bei professional and technical college, 2010, 9(5):33-34. 
[2] Yanhong Sun. Exploration on teaching reform of human anatomy and physiology in pharmacy specialty of higher vocational colleges [J]. Jiao Xun Shi Jian Yan Jiu, 2010.197-198.

[3] Shenghua Mei. Focus on ability training and actively carry out human anatomy and physiology reform [J]. Occupation education, 2010(6): 157-158.

[4] Dan Ji, Hua Li, Meimei Liu. The Application and Effect of Objective Teaching Approach in Human Physical Anatomy [J]. Education and teaching research, 2010(9): 90-91.

[5] Xuelong Ma. Teaching Exploration and Practice of Human Anatomic Physiology [J]. Journal of Huang Shan University, 2011, 13(3): 134-136.

[6] Yinlan Dong. Study on Human Anatomy and Physiology Experiments Teaching Reform [J]. Journal of Shanxi Normal University: Natural science edition, 2009, (23): 43-45.

[7] Mingsong Xiao, Song Wang, Weilai Yang, et al. Exploration of Teaching Reform in Human Anatomic Physiology Course-A Case Study of Pharmaceutical Preparations Specialty [J]. Journal of Anhui Science and Technology University, 2016, 30(2): 88-91.

[8] Daoli Zhu, Kangle Wang,Yitong Ma, et al. Application of Case Teaching and Project Tasks in the Teaching Reform of Human Anatomy and Physiology Course [J]. Animal Husbandry and Feed Science, 2014, 35(10): 58-62.

[9] Dandan Huang, Kaihua Sun. Research on the curriculum reform of human anatomy and physiology based on DQP academic background [J]. Strait Pharmaceutical Journal, 2018, 30(1): 63-65.

[10] Yuhua Pei. Discussion on the Teaching Reform of the Course of Human Anatomy and Physiology in Psychological Consultation [J]. School Party Building and Ideological Education, 2014. 52-53.

[11] Wenwei Yang, Lingyun Xue, Yong Yang. Reform and thinking on the teaching mode of human anatomy and physiology in biomedical engineering $[\mathrm{J}]$. Education teaching forum, 2014, (42): 82-84.

[12] Daoli Zhu, Kangle Wang, Shulin Xia, et al. Practice of Modern Educational Technology in Teaching Reform of Human Anatomy and Physiology Course [J]. Heilongjiang Animal Science and Veterinary Medicine, 2015, (08): 276-278.

[13] Aiping Wang, Dongfeng Jiang, Jinhua Xia, et al. The Research and Development of Network Teaching Platform on Anatomy and Physiology [J]. Journal of shangrao normal university, 2009, 29(6): 69-74. 